\title{
Conducting glasses
}

\author{
C S SUNANDANA
}

School of Physics, University of Hyderabad, Hyderabad 500 134,.India

\begin{abstract}
Ion-conducting tellurite glasses are built from trigonal bipyramidal $\mathrm{TeO}_{4}$ units. Neutron diffraction as well as Raman and IR spectroscopic studies have shown that there is a continuous transition from $\mathrm{TeO}_{4} \rightarrow \mathrm{TeO}_{3+1} \rightarrow \mathrm{TeO}_{3}$ as the alkali oxide content is progressively increased, non-bridging oxygens being created in the process. Electrical conduction in both single and mixed alkali tellurite glasses is satisfactorily explained by the interchange transport mechanism, based on the site-memory effect exhibited by the glass network.
\end{abstract}

Keywords. Ion conducting glasses; tellurite glasses; mixed alkali effect; electrical conduction; intercharge transport.

\section{Introduction}

Conducting glasses - essentially non-metallic in constitution (oxide or chalcogenide) could be of three types, depending on the nature of conducting species: (a) Electronic conducting: e.g. $\mathrm{As}_{2} \mathrm{~S}_{3}, \mathrm{~V}_{2} \mathrm{O}_{5}-\mathrm{Te}_{2}, \mathrm{CuO}-\mathrm{V}_{2} \mathrm{O}_{5}-\mathrm{TeO}_{2}$, (b) ion conducting: $\mathrm{Li}_{2} \mathrm{O}-$ $\mathrm{SiO}_{2}, \mathrm{AgI}-\mathrm{Ag}_{2} \mathrm{O}-\mathrm{B}_{2} \mathrm{O}_{3}$ and (c) mixed-conducting: $\mathrm{Na}_{2} \mathrm{O}-\mathrm{V}_{2} \mathrm{O}_{5}-\mathrm{B}_{2} \mathrm{O}_{3}$.

In the first category-dealt with by Ghosh (1994) - are semiconducting glasses (Sunandana and Bhatnagar 1984; Sunandana and Rao 1985), useful for switching and memory devices while the second category comprises solid electrolytes which transport ions only. The third category consists of glasses that transport both electrons and ions - a feature useful for solid state battery applications. Paramagnetic impurities such as $\mathrm{Fe}^{3+}$ often render ion conducting glasses mixed conductors (Balaya and Sunandana 1990b).

In this talk we shall focus exclusively on ion-conducting glasses. That a glass can be an effective medium of ion transport was dramatically established by Burt (1925) of R A Millikan's laboratory, through the ' $60 \mathrm{~W}$ electric bulb' experiment (figure 1). This experiment showed that a bulb partially immersed in a bath of molten sodium nitrate, when made to glow, allowed sodium ions to pass through its envelope, to combine with the electrons thermionically emitted from tungsten filament inside the bulb and to form $\mathrm{Na}$ atoms which eventually deposited on the cooler inner topside of the bulb.

Ionic oxide glass systems generally consist of a minimum of two components: an alkali oxide containing the mobile ion $\left(\mathrm{Li}_{2} \mathrm{O}\right)$ and the glass former $\left(\mathrm{B}_{2} \mathrm{O}_{3}\right)$. Thus we have alkali silicates, alkali borates, alkali phosphates, alkali germanates, and, of late, alkali tellurites where the alkali ions migrate through the glass network and conduct electricity. There are two essential aspects to ion conducting glasses: (i) basic structure, i.e. short range order, and changes introduced by added alkali oxide and (ii) (a) electrical conductivity as functions of concentration and temperature and (b) mixed alkali effect as observed in conductivity experiments. In what follows, the above aspects are delineated, with respect to alkali tellurite glasses. 


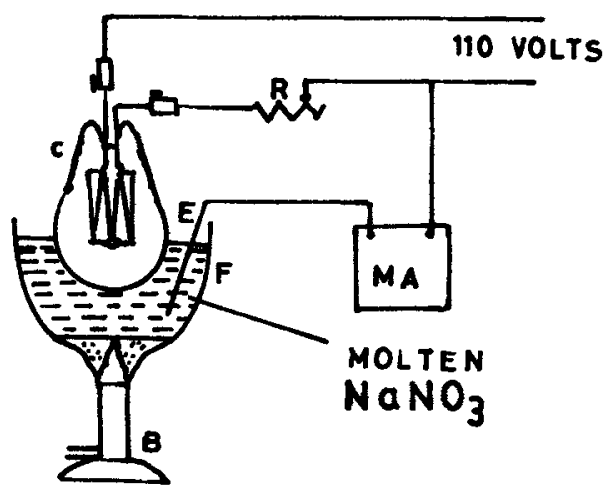

Figure 1. Burt's apparatus for electrolysis through glass bulb. (C: $40 / 60 \mathrm{~W}$ metal filament lamp; R: variable resistance, MA:milliammeter, E: thick copper wire electrode; F: iron crucibie; B: bunsen burner. This simple but spectacular experiment demonstrates conduction through glass as dramatically as Faraday's original experiment on $\mathrm{Na}_{2} \mathrm{SO}_{4}$ ).

\section{Basic structure of tellurite glasses}

Glass structure is important for conductivity in as much as the structure decides not only the potential barriers for the transport of mobile ions but also the mobile ion concentration itself. This structure changes both upon increasing temperature and concentration of the alkali components. Specifically, the structural information derived includes (i) the building block i.e. the $\mathrm{Te}-\mathrm{O}_{n}$ polyhedron involved in the formation of the glass network, (ii) the changes in the 'building block' structure as the conducting oxide component is added, and (iii) the presence and concentration of non-bridging oxygens (NBOs) in the glass network.

Empirically speaking, pure $\mathrm{TeO}_{2}$ is not expected to form a glass because (a) although the covalency of the Te-O bond favours glass formation (and polymorphism), the octahedral coordination of the $\mathrm{Te}-\mathrm{O}_{n}$ polyhedron is not conducive for glass formation (Sunandana 1994) and (b) the $\mathrm{Te}-\mathrm{O}_{n}$ polyhedron turns out to be too rigid (compared to $\mathrm{Ge}-\mathrm{O}_{n}$ ) to permit extensive distortion of the $\mathrm{Te}-\mathrm{O}$ bond necessary for stabilizing a random network.

Brady (1956) has shown through X-ray diffraction studies that a small percentage $\left(\sim 10 \mathrm{~mol} \%\right.$ ) of a 'promoter' (say $\left.\mathrm{Li}_{2} \mathrm{O}\right)$ is necessary for the formation of distorted octahedral $\mathrm{TeO}_{2}$ glass. The role of $\mathrm{Li}_{2} \mathrm{O}$ is to provide oxygens to break one of the edges of the octahedron-the building block of the brookite phase of $\mathrm{TeO}_{2}$ - to complete the octets of $\mathrm{Te}^{4+}$ and $\mathrm{Li}^{+}$. Thus while $\mathrm{O}$ 's of $\mathrm{Li}_{2} \mathrm{O}$ break the symmetry (locally), the $\mathrm{Li}^{+}$ions wholly occupy interstices in the loosened glass network.

The short-range order in alkali-oxide stabilized $\mathrm{TeO}_{2}$ glasses and the nature of the molecular groups in them have been investigated through neutron diffraction and Raman/IR spectroscopy.

Neutrons have been effectively used to determine the interatomic distances (e.g. $\mathrm{Ba}-\mathrm{O} / \mathrm{Li}-\mathrm{O}, \mathrm{Te}-\mathrm{O}, \mathrm{O}-\mathrm{O}$ ) and coordination number of ' $\mathrm{Te}$ and the changes in the latter as $\mathrm{BaO}$ or $\mathrm{Li}_{2} \mathrm{O}$ content is increased in the binary tellurite glasses (Neov et al 1979; Ueno and Suzuki 1983). The negative scattering length of $\mathrm{Li}$ has been exploited in exploring the Li-O distances (Neov et al 1979). The resolution of the pulsed neutron technique is good enough to distinguish between the axial and equatorial Te-O 

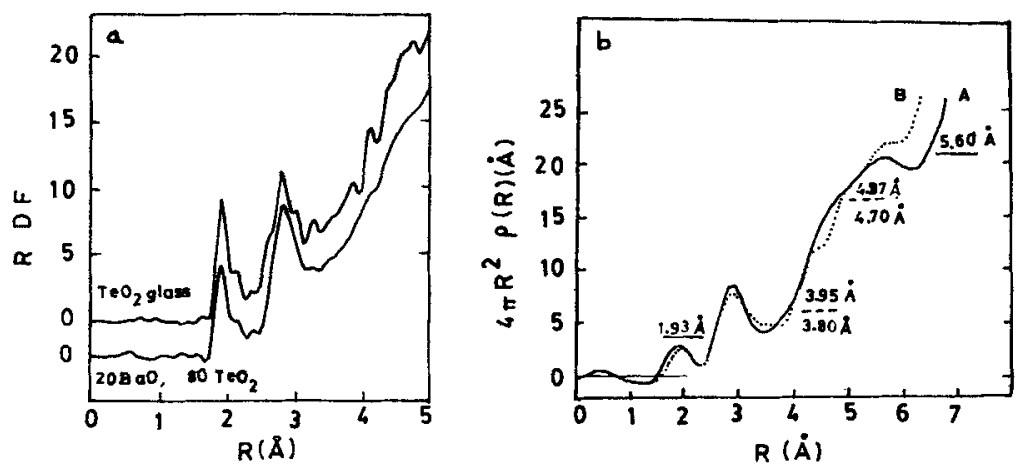

Figure 2. a. Radial distribution function (RDF) of $\mathrm{TeO}_{2}$ glass and $20 \mathrm{BaO} 80 \mathrm{TeO}_{2}$ glass obtained by pulsed neutron total scattering. Note that the first ( $\mathrm{Te}-\mathrm{O}$ bonding) peak has two sub peaks. The position of the first varies from 1.9-2.2 A depending on $\mathrm{BaO}$ content while the second is fixed at $2.18 \AA$. These two distances correspond to equatorial and axial Te-O bonds of the $\mathrm{TeO}_{4}$ unit (Ueno and Suzuki 1983) and b. RDF for $20 \mathrm{Li}_{2} \mathrm{O}-80 \mathrm{TeO}_{2}$ glass obtained from neutron diffractometry $(\lambda=1.06 \AA$ ) (A: Experimental curve; B: Theoretical curve based on structural diffusion model for amorphous $\mathrm{TeO}_{2}$ ). The differences are attributed to the influence of $\mathrm{Li}-\mathrm{O}$ distances, which is more profound after the first $(\mathrm{Te}-\mathrm{O})$ and second $(\mathrm{O}-\mathrm{O}$ and $\mathrm{Te}-\mathrm{O}$ ) peaks, which occur at 1.93 and $2.90 \AA$. Note that the resolution is poorer here (Neov et al 1979).

distances in $\mathrm{TeO}_{4}$ by way of the split first peak in the radial distribution function (figure 2).

Two major conclusions that emerge from these studies are: (i) that the basic building block of the $\mathrm{TeO}_{2}$ glass structure is a trigonal bipyramid (tbp) $\mathrm{TeO}_{4}$, and (ii) that upon addition of alkali-oxides the tbp gradually changes through $\mathrm{TeO}_{3+1}$ to trigonal pyramid $\mathrm{TeO}_{3}$, in the manner of a continuous structural transition, quite unique to tellurite glasses and not known to occur in borate, silicate, germanate and phosphate glasses.

The second result is important from the point of view of ionic conduction because the $\mathrm{TeO}_{4} \rightarrow \mathrm{TeO}_{3}$ transformation involve the continuous creation of non-bridging oxygens.

Based on these data, the two-dimensional model for the tellurite glass network turns out to be

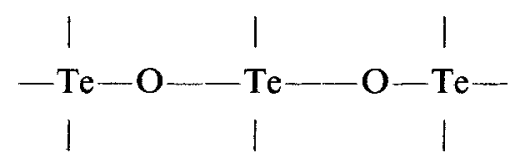

Note that the longer $(>2.08 \AA) \mathrm{Te}-\mathrm{O}$ bond is the axial while the shorter $(<1.9 \AA)$ one is the equatorial bond of the deformed $\mathrm{TeO}_{4}$ tbp.

IR and Raman spectroscopy - particularly the latter - have been used to (i) identify the building blocks in $\mathrm{TeO}_{2}$ glass and (ii) to monitor the transformation of these building blocks as the alkali/alkaline earth oxide component is varied.

Pure $\mathrm{TeO}_{2}$ glass gives an IR peak around $660 \mathrm{~cm}^{-1}$ characteristic of the $\mathrm{Te} \sim \mathrm{O}$ stretching of $\mathrm{TeO}_{4}$ (Ueno and Suzuki 1983). As $\mathrm{BaO}$ is added, this bond splits, the split component gradually developing in intensity signalling the $\mathrm{TeO}_{4} \rightarrow \mathrm{TeO}_{3+1}$ transformation. 

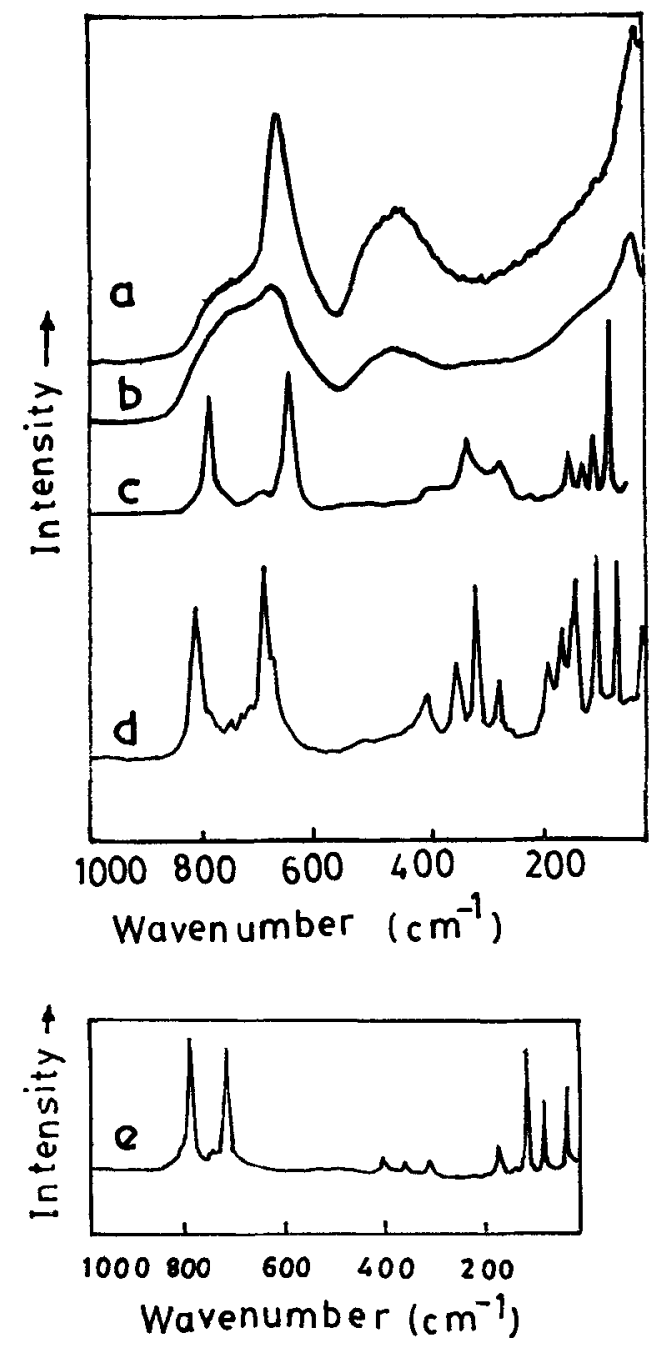

Figure 3. Raman spectra of (a) $\mathrm{TeO}_{2}$ glass, (b) $30 \mathrm{Li}_{2} \mathrm{O}-70 \mathrm{TeO} \mathrm{O}_{2}$ glass, (c) $\alpha$ - $\mathrm{Li}_{2} \mathrm{Te}_{2} \mathrm{O}_{5}$ crystal, (d) $\beta$ - $\mathrm{Li}_{2} \mathrm{Te}_{2} \mathrm{O}_{5}$ crystal and (e) $\mathrm{Li}_{2} \mathrm{TeO}_{3}$ crystal.

Sekiya et al (1992) carried out a comprehensive Raman spectral study of $\mathrm{A}_{2} \mathrm{O}-\mathrm{TeO}_{2}$ $(\mathrm{A}=\mathrm{Li}, \mathrm{Na}, \mathrm{K}, \mathrm{Pb}, \mathrm{Cs}$ and $\mathrm{Tl})$ glasses. Figure 3 shows Raman spectra for $\mathrm{TeO}_{2}$ and 30 $\mathrm{Li}_{2} \mathrm{O}-70 \mathrm{TeO}_{2}$ glasses, $\alpha$ and $\beta \mathrm{Li}_{2} \mathrm{Te}_{2} \mathrm{O}_{5}$ as well as $\mathrm{Li}_{2} \mathrm{TeO}_{3}$ crystalline compounds, the latter being used to assign the Raman peaks in the former. There are basically five peaks at about $780,720,665,615$ and $450 \mathrm{~cm}^{-1}$ the first four of which arise from the asymmetric stretching vibrations of $(I)$ in the $\mathrm{TeO}_{2}$ glass, while the fifth one represents the symmetric stretching and bending vibration of the $\mathrm{Te}-\mathrm{O}-\mathrm{Te}$ linkages formed by vertex sharing of $\mathrm{TeO}_{4}$ tbp's, $\mathrm{TeO}_{3+1}$ polyhedra and $\mathrm{TeO}_{3}$ trigonal pyramids. The spectra of $\alpha$ - and $\beta$ - $\mathrm{Li}_{2} \mathrm{Te}_{2} \mathrm{O}_{5}$ reflect trends in paratellurite $\left(\alpha-\mathrm{TeO}_{2}\right)$ and tellurite $\left(\beta-\mathrm{TeO}_{2}\right)$ in that they represent $\mathrm{Te}-\mathrm{O}$ stretching and $\mathrm{Te}_{3+1}-\mathrm{O}-\mathrm{Te}_{3+1}$ asymmetric vibration of the $\mathrm{TeO}_{3+1}$ polyhedron in the $\alpha$-form and only the latter in the $\beta$-form where two $\mathrm{TeO}_{3+1}$ units share a common edge to form $\mathrm{Te}_{2} \mathrm{O}_{6}$ and each Te has one 


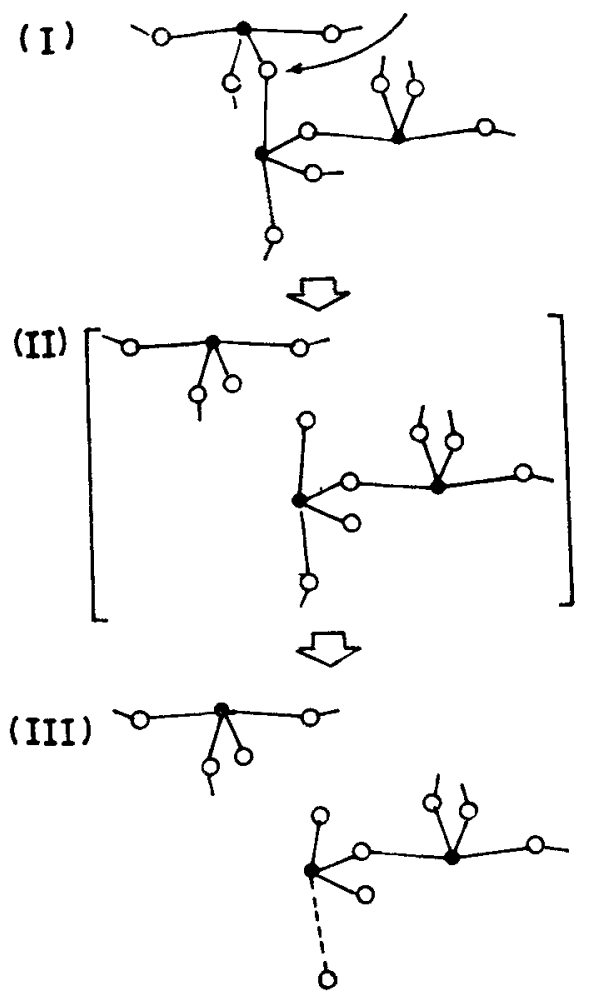

Figure 4. A mechanism for the structural change in the $\mathrm{TeO}_{2}$ glass network from $\mathrm{TeO}_{4}(\mathrm{tbp})$ to $\mathrm{TeO}_{3+1}$ polyhedra induced by addition of modifier oxide.

I: $\mathrm{TeO}_{2}$ glass structure with oxygen linked $\mathrm{TeO}_{4}$ units. $\mathrm{Te} ; \mathrm{O}$, oxygen;- - short bond, long bond. Arrow indicates modifier entry.

II: Breaking of I by addition of modifier oxide and creation of axial (long) and equatorial (short) Te-O bonds. Square bracket indicates that this step is an unstable intermediate one because the long bond is unstable.

III: Formation of $\mathrm{Te} \cdots \mathrm{O}$ bond and creation of $\mathrm{TeO}_{3+1}$ group (Sekiya et al 1992).

NBO. In $\mathrm{Li}_{2} \mathrm{TeO}_{3}, \mathrm{Te}-\mathrm{O}^{-}$stretching produces two strong peaks, while bending of $\mathrm{TeO}_{3}^{2-}$ produces three weak peaks around $360 \mathrm{~cm}^{-1}$, characteristic of isolated $\mathrm{TeO}_{3}^{2-}$ ions, with three equivalent $\mathrm{Te}-\mathrm{O}$ bonds. While $\mathrm{Li}_{2} \mathrm{Te}_{2} \mathrm{O}_{5}$ represents the crystalline equivalent of $33 \mathrm{Li}_{2} \mathrm{O}-67 \mathrm{TeO}_{2}$ glass, $\mathrm{Li}_{2} \mathrm{TeO}_{3}$ represents a hypothetical $50 \mathrm{Li}_{2} \mathrm{O}-50$ $\mathrm{TeO}_{2}$ glass, where the transformation from $\mathrm{TeO}_{4}$ to $\mathrm{TeO}_{3}$ is complete.

Based on these data, a mechanism for the structural change from $\mathrm{TeO}_{4}$ tbp to $\mathrm{TeO}_{3}$ induced by the addition of $\mathrm{A}_{2} \mathrm{O}$ component into the glass network composed of $\mathrm{TeO}_{4}$ tbp's has been suggested. A few mole percent $\mathrm{A}_{2} \mathrm{O}$ added to $\mathrm{TeO}_{2}$ break the $\mathrm{Te}-\mathrm{O}-\mathrm{Te}$ linkage and creates two types of NBO's. The stable Te- $\mathrm{O}^{-}$and the unstable Te--- $\mathrm{O}^{-}$. $\mathrm{TeO}_{4}$ with the latter is unstable and thus becomes $\mathrm{TeO}_{3+1}$. One $\mathrm{Te}---\mathrm{O}^{-}$bond shortens while the other $\mathrm{Te}-\cdots \mathrm{O}^{-}$bond elongates, forming a Te $\cdots \mathrm{O}$ bond (figure 4). In glasses with higher alkali content, cleavage of continuous network leads to an increase of the fraction of $\mathrm{TeO}_{3+1}$ polyhedra. Elongation of the $\mathrm{Te} \cdots \mathrm{O}$ bond of $\mathrm{TeO}_{3+1}$ and its cleavage by transfer of electron and alkali ion finally leads to the formation of trigonal prismatic $\mathrm{TeO}_{3}$ units. 
As may be noted from the above discussion, creation of NBO's is an important aspect of the continuous transformation of the tellurite glass structure induced by the alkali oxide. This important defect (akin to the dangling bond is amorphous silicon) plays a vital role in the alkali-ion transport in both single alkali and mixed-alkali tellurite glasses.

Coming back to the ' $60 \mathrm{~W}$ bulb experiment' of figure 1, two questions need to be asked, particularly in the context of structural aspects discussed above: (i) how are ions transported across tellurite glasses of single (e.g. $\left.\mathrm{Li}^{+}\right)$and mixed $\left(\mathrm{Li}^{+}\right.$and $\mathrm{Na}^{+}$) alkali-types? and (ii) what role does the short-range order play in controlling the concentration and mobility of these ions?

\section{Electrical conduction in tellurite glasses}

The ionic conductivity ( $\sigma$ ) of lithium (and silver) tellurite glasses has been investigated by a number of workers (Sunandana and Kumaraswami 1986; Martins Rodrigues and Duclot 1988; Tanaka et al 1988, 1991; Balaya and Sunandana 1990a, b, 1992, 1993, 1994; Rojo et al 1990). Crystalline $\mathrm{Li}_{2} \mathrm{Te}_{2} \mathrm{O}_{5}(\alpha$ and $\beta$ ) has been studied by Cachau-Herreillat et al (1981). The temperature dependence of $\sigma$ invariably follows the Arrhenius behaviour $\sigma=\sigma_{0} \exp \left(-E_{\mathrm{a}} / k T\right)$, indicating thermally activated mobility as the underlying cause. Alkali-oxide concentration dependence of pre-exponential factor $\left(\sigma_{0}\right)$ and activation energy $\left(E_{\mathrm{a}}\right)$ show opposite trends, with the former increasing and the latter decreasing upon increase of say, $\mathrm{Li}_{2} \mathrm{O}$ (figure 5). Assuming that the tiny $\mathrm{Li}^{+}$ ions occupy interstices close to NBO's in the tellurite glass network, the question is how does the $\mathrm{Li}^{+}$ion overcome the random potential barriers offered by the interconnected $\mathrm{TeO}_{4}$ units?

Before discussing the specific case of conduction mechanism in tellurite glasses, let us discuss a recently developed (Maass et al 1992) unified theory of ion migration processes in glass. This theory is based on the experimental evidence that cations (e.g. $\left.\mathrm{Li}^{+}\right)$in glass $\left(\right.$e.g. $\left.\mathrm{Li}_{2} \mathrm{O}-\mathrm{SiO}_{2}\right)$ create and maintain their own environment. This $\mathrm{Li}^{+}$ migration in $\mathrm{SiO}_{2}$ glass involves the creation and maintenance of a favourable oxygen environment around a given $\mathrm{Li}^{+}$interstitial. Next it is postulated that a site-memory

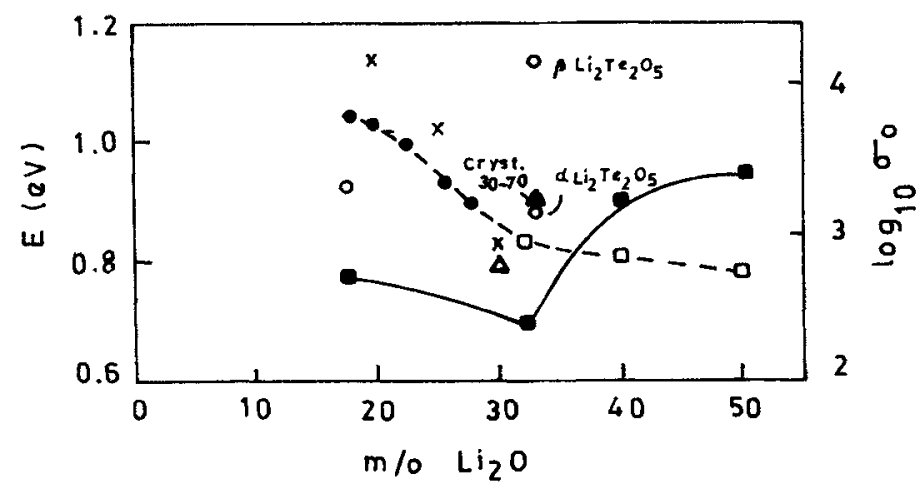

Figure 5. Activation energies $\left(E_{\mathrm{a}}\right)$ and preexponential factor $\left(\sigma_{0}\right)$ as function of $\mathrm{Li}_{2} \mathrm{O}$ content in $\mathrm{Li}_{2} \mathrm{O}-\mathrm{TeO}_{2}$ glasses. Data from: $\square$, Mazurin 1985, × Tanaka et al (1988), O, $\square$ Rojo et al (1990), $\alpha, \beta \mathrm{Li}_{2} \mathrm{Te}_{2} \mathrm{O}_{5}$, Cachau-Herriellat et al (1981), $\Delta, \triangle$ Balaya and Sunandana (1993). 


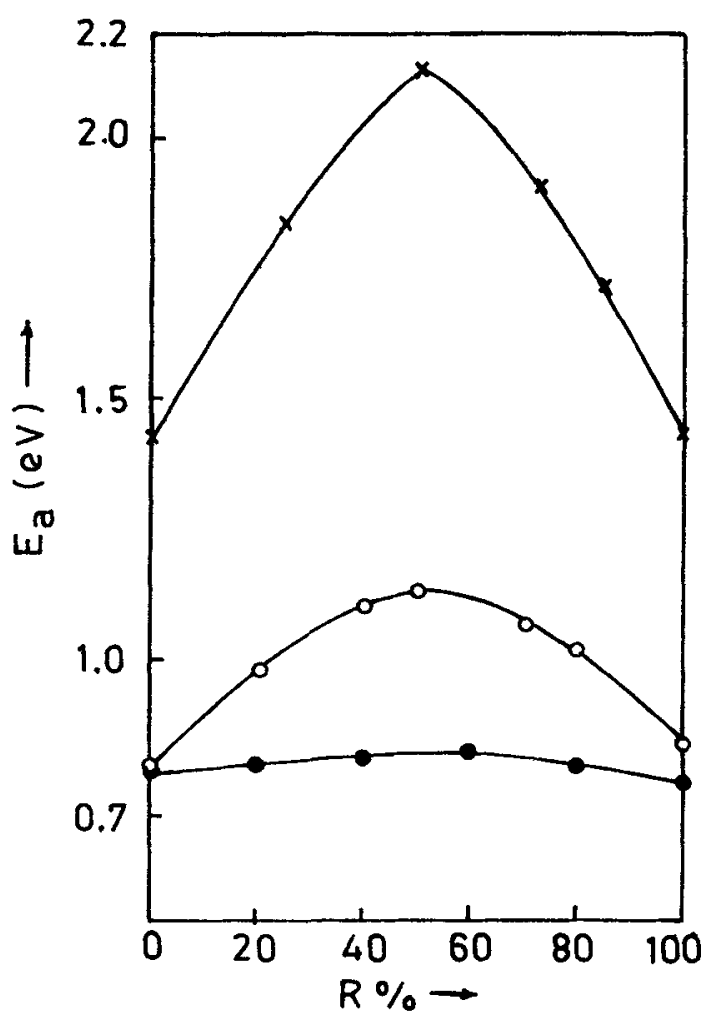

Figure 6. Mixed alkali effect observed in the conductivity activation energy $\left(E_{\mathrm{a}}\right)$ of $30\left[(1-x) \mathrm{Na}_{2} \mathrm{O} \cdot x \mathrm{~K}_{2} \mathrm{O}\right]: 70 \mathrm{GeO}_{2}(\times \times \times), 30\left[(1-x) \mathrm{Li}_{2} \mathrm{O} \cdot x \mathrm{Na}_{2} \mathrm{O}\right]: 70 \mathrm{~B}_{2} \mathrm{O}_{3}(\mathrm{O} O \mathrm{O})$ and $30\left[(1-x) \mathrm{Li}_{2} \mathrm{O} \cdot x \mathrm{Na}_{2} \mathrm{O}\right): 70 \mathrm{TeO}_{2}(-)$. $R$ is the fraction of the second alkali relative to the total alkali concentration (e.g. $\mathrm{Na} /\left(\mathrm{Na}^{+} \mathrm{Li}\right)$ ). The maximum deviation is observed when $R=0.5$. For data sources see text.

effect exists in glass whereby the glass framework itself 'remembers' the previous positions of the cations. One could thus visualize the formation of distinct conducting pathways for the mobile ion. A mobile ion $\left(\mathrm{A}^{+}\right)$with given surroundings hops or jumps to a vacant site $A$ created by a similar ion but not to site $B$ with different surroundings i.e. an unfavourable potential barrier. Thus a preferred pathway would be $A^{+} \rightarrow \bar{A}$ $--\bar{A}---\bar{A}$ but not $A^{+} \rightarrow \bar{B}---\bar{A}---\bar{A}$ because the latter would be an energetically more expensive process. The essential requirement for the model is thus a matching of the available sites for a given mobile ion. If the number of such 'matched sites' increase upon increase of alkali-oxide concentration, besides, of course the number of mobile ions itself (or temperature) the conductivity would increase.

The main result of this model is that $\sigma \sim C_{\mathrm{A}}^{\gamma}$ where $\gamma \sim 1 / T$ so that the activation energy is proportional to $\log C_{\mathrm{A}}$.

Now consider a glass with two mobile ions $\mathrm{A}^{+}$and $\mathrm{B}^{+}$with radii $r_{\mathrm{A}}$ and $r_{\mathrm{B}}$ such that $r_{\mathrm{B}}>r_{\mathrm{A}}\left(\mathrm{e} . \mathrm{g} . \mathrm{Li}^{+}\right.$and $\left.\mathrm{Na}^{+}\right)$. As the concentration of $\mathrm{B}$ relative to the total concentration of $\mathrm{A}$ and $\mathrm{B},(x)$, increases the theory quantitatively predicts a maximum in the ratio of total diffusion coefficient to the d.c. conductivity at $x \approx 0.5$. This is the so-called mixed alkali effect (MAE) - the experimental observation (that $\sigma(T)$ goes through 
a minimum and $E_{\mathrm{a}}$ goes through a maximum at $x \approx 0.5$ ) that has defied a comprehensive explanation for nearly seven decades now. Figure 6 compares the MAE as observed in the conductivity activation energy with (Na, K) germanate (Ivanov 1964), (Li, Na) borate (Kawamura et al 1987) and tellurite (Balaya and Sunandana 1994) glasses of 30-70 composition. Note that the effect is smallest in tellurite glasses and largest in germanate glasses. ( $\mathrm{Li}, \mathrm{Na}$ ) germanate glasses are also expected to show a similar effect. It would be interesting to study MAE in the glasses $30(\mathrm{Li}, \mathrm{Na})_{2} \mathrm{O}-$ $(70-x) \mathrm{GeO}_{2} x \mathrm{TeO}_{2}$, to see if the effect can be understood in terms of changes in the short range order induced by partial replacement of $\mathrm{GeO}_{2}$ by $\mathrm{TeO}_{2}$. Although the percolation-type model described above offers a convincing explanation for single and mixed alkali glasses, it glosses over the structural peculiarities of the various glasses and the actual microscopic events that lead to ion migration and conductivity.

Uchino et al (1992) looked at ionic transport in single and mixed alkali glasses by modelling the local structure of alkali silicate glasses. Based on $a b$ initio molecular orbital calculations on clusters such as $\mathrm{H}_{4} \mathrm{Si}_{2} \mathrm{O}_{7} \mathrm{Li}_{2}$ and $\mathrm{H}_{4} \mathrm{Si}_{2} \mathrm{O}_{7} \mathrm{Li} \mathrm{Na}$ which simulate the local scale structure of $\mathrm{Li}_{2} \mathrm{O} \cdot 2 \mathrm{SiO}_{2}$ and $0.5 \mathrm{Li}_{2} \mathrm{O}-0.5 \mathrm{Na}_{2} \mathrm{O} \cdot 2 \mathrm{SiO}_{2}$, they have proposed an ion interchange transport mechanism, which seems to be applicable to $\mathrm{Li}^{+}$conduction in lithium tellurite and MAE in lithium-sodium tellurite glasses (Balaya and Sunandana 1994).

In the tellurite glasses, let us assume that there are bound $\mathrm{Li}^{+}$, unbound $\mathrm{Li}^{+}$near NBOs and of course $\mathrm{Te}^{4+}$ bound by 4 oxygens. The interchange transport process involves the following steps:

$$
\begin{aligned}
\text { I. } \mathrm{Li}^{+} \text {(bound) } & \rightarrow \mathrm{Li} \text { (unbound) } \\
\text { II. } \mathrm{Te}^{4+} & \rightarrow\left[\mathrm{Li}^{+} \text {(bound) }\right] \\
\text { III. } \mathrm{Li}^{+} \text {(bound) } & \rightarrow\left(\mathrm{Te}^{4+}\right] \\
\text { IV. } \mathrm{O}^{--} & \rightarrow \mathrm{O}^{-}(\mathrm{NBO}) .
\end{aligned}
$$

Note that steps II and III involve interchange of $\mathrm{Li}^{+}$with $\mathrm{Te}^{4+}$ which is the main process responsible for ion transport. Note also that the fourth step generates NBOs. This interchange transport process essentially consists in establishing conduction pathways, and is in the spirit of the model of Maass et al (1992). With reference to figures 4 and 6 , it is important to note that this single mechanism operates in tellurite glasses, be they single alkali glasses where at low alkali concentration, the conduction paths are not yet established, or mixed alkali glasses, in which the minor alkali ion make uncorrelated motions in the network. Questions for the future would be the following:

(1) Is the overall interchange transport process energetically favourable? If so, how does one experimentally account for say, the $\mathrm{Si}^{4+}$ (or $\mathrm{Te}^{4+}$ ) hop from its original position to the bound $\mathrm{Li}^{+}$vacancy?

(2) Kinetically speaking, what are the rates for the four steps in the process? Are these rates measurable?

(3) Does the continuous exchange of $\mathrm{Si}^{4+} / \mathrm{Te}^{4+}$ with $[\mathrm{Li}$ (bound)] not mean a local collapse of the glass network? Is this 'collapse time' much less than some average relaxation time? 


\section{Conclusions}

Ion-conducting tellurite glasses are built from trigonal bipyramidal $\mathrm{TeO}_{4}$ units. Neutron diffraction as well as Raman and IR spectroscopic studies have shown that there is a continuous transition from $\mathrm{TeO}_{4} \rightarrow \mathrm{TeO}_{3+1} \rightarrow \mathrm{TeO}_{3}$ as the alkali oxide content is progressively increased, non-bridging oxygens being created in the process. Electrical conduction in both single and mixed alkali tellurite glasses is satisfactorily explained by the interchange transport mechanism, based on the site-memory effect exhibited by the glass network.

\section{Acknowledgement}

I thank my former students Mr T Kumara Swami and Dr P Balaya who participated in the research on tellurite glasses.

\section{References}

Balaya $\mathrm{P}$ and Sunandana C S 1990a Recent advances in fast ion conducting materials and devices (eds) B V R Chowdari et al (Singapore: World Scientific) p. 539

Balaya $P$ and Sunandana C S 1990b Recent advances in fast ion conducting materials and devices (eds) B V R Chowdari et al (Singapore: World Scientific) p. 543

Balaya P and Sunandana C S 1992 Solid state ionics: materials and applications (eds) B V R Chowdari et al (Singapore: World Scientific) p. 527

Balaya P and Sunandana C S 1993 J. Noncryst. Solids 162253

Balaya P and Sunandana C S 1994 J. Noncryst. Solids 17551

Brady G W 1956 J. Chem. Phys. 27300

Burt R C 1925 J. Opt. Soc. Am. 1187

Cachau-Herriellat D et al 1981 J. Solid State Chem. 37352

Ghosh A 1994 This proceedings

Ivanov A O 1964 Sov. Phys. Solid State 51933

Kawamura J, Sato R, Mishina S and Shimoji M 1987 Solid State Ionics 25155

Maass P, Bunde A and Ingram M D 1992 Phys. Rev. Lett. 683064

Martins Rodrigues A C and Duclot M J 1988 Solid State lonics 28-30 729

Mazurin O V et al 1985 Handbook of glass data, physical sciences data 15 Part B (Amsterdam: Elsevier) p. 672 Neov Set al 1979 J. Phys. C12 2475

Rojo J M et al 1990 J. Noncryst. Solids 116167

Sekiya T et al $1992 \mathrm{~J}$. Noncryst. Solids 144128

Sunandana C S 1994 in Solid state ionic materials (eds) B V R Chowdari et al (Singapore: World Scientific) p. 301

Sunandana C S and Bhatnagar A K 1984 J. Phys. C17 467

Sunandana C S and Kumaraswami T 1986 J. Noncryst. Solids 85247

Sunandana C S and Rao K S 1985 Phys. Status Solid (a)90 681

Tanaka K et al 1988 J. Noncryst. Solids 103250

Tanaka K et al 1991 J. Noncryst. Solids 135211

Uchino T et al 1992 J. Noncryst. Solids 14626

Ueno M and Suzuki K 1983 Kakuriken Kenkyo Hokoku (Tohoku Univ.) 16349 